\title{
Why do circadian biorhythms age?
}

\author{
Josef Berger
}

Institute of Biophysics and Medical Engineering, Faculty of Health and Social Studies, University of South Bohemia in České Budějovice, Czech Republic

\begin{abstract}
Summary
Circadian biorhythms change with age and such changes are caused by the loss of both the time and the space structure. These alterations of biorhythms are associated with poor health and the end of life but we do not know the extent to which they represent cell clock system injury. It seems that ageing of biorhythms in mammals, i.e. including humans, is caused by the ability of suprachiasmatic nuclei to drive oscillations in other tissues. Social synchronization extending photic stimuli, which diminishes during degeneration of nerve and optic system, enhances the quality of life and therefore further studies of the influence of health and social care systems on circadian rhythms could contribute to the lengthening of life.
\end{abstract}

Key words: ageing - rhythm - regulation - synchronizer - quality of life

\section{INTRODUCTION}

Living systems have both a space and a time structure. The time structure is formed by the interactions between transient stages during development, and biorhythms. Biorhythms are regular incident phenomena in living organisms (chronobiology). Biorhythms can affect sensitivity to drugs (chronopharmacology, chronotoxicology), symptoms of various diseases (chronopathology) and many other interactions between an organism and its environment.

To measure biorhythms, we can use the equation $\mathrm{Y}(\mathrm{t})=\mathrm{M}+\mathrm{A} \cos (\omega \mathrm{t}+\Phi)$, where $\mathrm{M}$ is mesor, $\mathrm{A}$ is amplitude, $\omega$ is angle rate, $\mathrm{t}$ is time and $\Phi$ is the point of fiixed rhythm maximum, the so-called acrophase. This equation is frequently used, but real biorhythms are more or less irregular.

Biorhythms with a period of 22 to $26 \mathrm{hrs}$ are called circadian (circa $=$ about, dian $=$ day), those with a period shorter than $22 \mathrm{hrs}$ are ultradian, and those with a period longer than $26 \mathrm{hrs}$ are infradian. Circannual rhythms have a period of 10-14 months. Circadian rhythms are an evolutionary adaptation to day/night alternations, that is, an adaptation to the environmental changes caused by the Earth's rotation. As circadian rhythms are frequently the object of study, we have concentrated on them in this article.
Ageing is a continuous process which starts at birth. The progressive decrease in physiological capacity and the reduced ability to respond to environmental stresses lead to increased susceptibility and vulnerability to diseases (see Troen 2003). Ageing is a multifold process involving many genes and many metabolic pathways.

Among a number of hypotheses, the theory of oxidative stress seems to be popular (cf. Miquel 2002, Hofhaus et al. 2003): radical oxygen species, which are by-products of oxidative phosphorylation in mitochondria, damage intracellular biopolymers including mtDNA; and damaged molecules of mtDNA can accumulate within cells. Since oxygen is both necessary for living cells and a source of free radicals, ageing is an unavoidable characteristic of living systems.

Telomeres, the non-coding sequences at the end of chromosomes, in the absence of telomerase shorten with each cell division and the percentage of short telomeres increases with age in many tissues except brain tissue (cf. Rensing et al. 2001, Cherif 2003). Telomere shortening in human beings contributes to mortality in many age-related diseases. Replicative senescence of cultured Werner syndrome fibroblasts is a telomere-induced event (Davis et al. 2003). Earlier ageing after telomere shortening, which is caused by an infection burden, could lead to the ageing of immune cells and 
decreased immune surveillance and this predisposes to cancer (Sastry and Parikh 2003). The rate of telomere shortening can be modulated by oxidative stress (Saretzki and von Zglinicki 2002).

In human subjects and mammals, ageing may be the process which supports the prevention of malignant reversion and therefore paradoxically makes it possible to achieve maximal lifespan. Ageing can be influenced by many environmental factors, e.g. important nutritional factors (see Miquel 2002). The pioneer work of Pittendrigh and Minis (1972) discovered, that biorhythms could also influence lifespan: the lifespan of Drosophilas decreases when these insects are subjected to a 21 or a $27-\mathrm{h}$ day instead a $24-\mathrm{h}$ day (with light/dark cycle $12 / 12 \mathrm{~h}$ ).

\section{CIRCADIAN RHYTHMS IN HUMAN SUBJECTS AND THE ENVIRONMENT}

As human physiology and behaviour can be modified by biorhythms, we can ask which environmental stimuli can influence our rhythms and benefit our health. It was thought for many years that social events are the most important synchronizers of human biorhythms. More recent findings have documented that the most important synchronizer of human circadian rhythms (i.e. rhythms with a period of about $24 \mathrm{hrs}$ ) is light, although there are many questions about this mechanism still to be answered (see Usui 2000).

Photons are absorbed by retina photopigments and neural signals are generated in the retinohypothalamic tract. Photic stimuli are projected into the mammalian suprachiasmatic nucleus of the hypothalamus (cf. Ibata et al. 1999). Surgical destruction of suprachiasmatic nuclei aborts many circadian rhythms in mammals (cf. MeyerBernstein et al. 1999). This nucleus regulates the synthesis of the melatonin, a hormone produced by the pineal gland; photic stimuli suppress melatonin synthesis (Brainard et al.1997). The endogenous rhythm of melatonin synchronizes light/dark regime dependent circadian rhythms (Illnerova and Sumova1997, Shanahan et al.1997).

Although the causes are different, totally blind people and night shift workers have in common recurrent bouts of insomnia and wake-time sleepiness that cause asynchrony of sleep and wake times with their endogenous circadian rhythms. Exogenous melatonin given at the optimal circadian time can synchronize several biorhythms (Sack and Lewy 1997).

Thus, both a good light regime and intensity are necessary for human health including adaptation to night work and subsequent recovery (Bougrine et al.
1995). Morning bright light is a powerful synchronizer, it also reduces the frequency of behaviour disorders in elderly men with dementia (Mishuma et al. 1994). Nevertheless, non-photic stimuli play their role in the synchronization of rhythms, too (cf. Mrosovsky 1996).

\section{SENESCENCE IN PHYSIOLOGICAL RHYTHMS}

Biorhythms change during ontogenesis; they can be modified in both children and the elderly. Older individuals have higher scores for their activity in the morning than young men (Atkinson et al. 1992). A growing number of published papers indicate that one of the important changes in both older men and animals is the loss of function of the circadian clock. In this part of our article, we concentrate on a discussion of the general features of "old" rhythms and age-related changes in wake-rest activity that can be a prognostic factor of life span in older human subjects.

An increased tendency to low amplitude, loose internal synchronization and poor response to external environmental time queues are documented for many characteristics of both human subjects and animals (Richardson et al. 1982, Brock 1991, Vansomeren et al. 1993, Atkinson et al. 1994, Garciapatterson et al. 1996, Forsling 1998, Driver 2000, Weinert 2000, Van Someren et al. 2002). A shortened period of circadian rhythms was observed sometimes in old laboratory animals and elderly humans (Witting et al. 1994, Deuschle 1997, Weinert 2000).

Although the tendency to alteration of the circadian rhythm, mentioned above, has been documented in many publications, several physiological rhythms change in the elderly in different ways. For example, the mesor of circulating neutrophils is higher in old men than in young men with unchanged amplitude (Swoyer et al. 1989). As neutrophils play a critical role in the inflammation process, which is more frequent in the elderly, such observations seem to be logical in the framework of physiological regulations. Circadian variations in many other haematological characteristics are also evident (cf. Berger 1987) and these rhythms originate in both the circadian rhythm of physiological needs (Sletvold et al. 1988) and in blood cell production. Although the mechanism of many age-related changes in the circadian rhythm of haemopietic and blood cell numbers remains unknown, it seems that these variations are of a physiologic rather than a genetic origin.

Sleep disruption is common in the elderly and it has been suggested that these age-related alterations 
could reflect fundamental changes in the circadian system (cf. Billiard 1993). Various types of sleep disorders are associated with ageing (irregular sleepwake rhythms, insomnia etc.) and affect the elderly. Sleep disturbance is associated with impaired quality of waking life and it is a risk factor for institutionalization and mortality (cf. Pollak et al. 1992, Mishima et al. 1994).

Less distinction between day and night with unwanted sleeps during the day and unwanted wakefulness in the night was shown when comparing old with young people. (cf. Monk et al. 1991). The loss of the circadian system in the central nervous system results in impaired timing and quality of sleep with consequent behaviour problems (Driver 2000).

Interactions between the circadian system and sleep timing and consolidation, which are very important for the process of ageing, are altered in the elderly (Duffy and Czeisler 2002). Nevertheless, circadian periods of the melatonin, core body temperature, and cortisol are essentially identical in young and elderly subjects (Czeisler et al. 1999). There are some significant changes in humans older than 50 years (cf. Lunenfeld 2002), and other significant changes were documented for men older than 65 years (e.g. Blanker et. al. 2002).

The susceptibility to photic and nonphotic cues is decreased, and the number of functioning neurons in the suprachiasmatic nucleus is also lowered with advancing age (Weinert 2000). Photic stimuli can be also slightly eliminated by the degeneration of the optic system in senescence (cf. Hinton et al. 1986). But also, several rhythms do not change during senescence, for example circadian rhythms in erythropoietin serum levels were found unchanged in elder healthy peoples (Pasqualetti and Casale 1997).

The role of gender in the age-dependent changes of rhythms seems to be important. In evaluating temperature rhythm, which is relatively stable (Weitzman and Kripke 1981), it was found that elderly women have significantly higher amplitude $\left(0.23{ }^{\circ} \mathrm{C}\right)$ than older men $\left(0.17{ }^{\circ} \mathrm{C}\right)$ (Czeisler et al. 1992); the amplitude in young men is higher $\left(0.28{ }^{\circ} \mathrm{C}\right)$ than the amplitude in older men, also. The objective sleep quality of women is better than that of men (Reynolds et al. 1991). However, a lower amplitude of circadian rhythms seems to be a good marker of poorer tolerance to the stress of night work (Reinberg at al. 1984). Older men (more than 50) poorly resynchronize their biorhythms following long distance flight involving a change of time zone (Gander et al. 1993).

We can summarize by saying that biorhythms in the elderly change simultaneously with degeneration of the part of the nervous system which synchronizes peripheral oscillators and such changes are individually specific.

\section{REGULATION OF BIORHYTHMS AND AGEING}

It has been shown that there are several intracellular molecules which are important in both the ageing process and biorhythms notwithstanding our incomplete knowledge of ageing mechanisms.

Melatonin, an antioxidant and a hormone of the pineal gland, is (i) the synchronizer of many circadian rhythms and seasonal adaptations, (ii) a free-radical scavenger, (iii) an endogenous sleepinducer, and (iv) an anti-ageing agent (Olde Rikert and Rigaud 2001, Pandi-Perumal et al. 2002). Melatonin also influences reproduction, carcinogenesis and ageing (cf. Edmunds Jr 1994, Blask et al. 2002, Bubenik 2002, Mayo et al. 2002, Winczyk et al. 2002, Collins et al. 2003). Melatonin production can decline with age (Garciapatterson et al. 1996. Terron et al. 2002) but this phenomenon seems to be very individual for different human subjects (Zeitzer et al. 1999). The higher age is also associated with a shift in the acrophase (Sharma et al. 1989, Thomas and Miles 1989). Exogenous melatonin can prevent some undesirable ageing effects (Lunenfeld 2002). A decline in the superoxide anion, among others in relation to oxidative metabolism, was observed simultaneously with the increase in phagocytic function (Terron et al. 2002), and an increase in $\operatorname{IgG}_{1}$ and $\operatorname{IgM}$ responses (Akbulut et al. 2001). There is evidence of the therapeutic effects of melatonin, but further clinical trials are necessary as the mechanisms of melatonin effects remain to be determined.

Nitric oxide seems to be also involved in the regulatory events of the circadian rhythm. Its release from the hyxpothalamus and anterior pituitary gland is apparently induced by leptins (Mastronardi et al. 2002). This is very interestig as leptins are produced by adipocytes, the number and size of which are influenced by age (Rozman et al. 1989) and nutrition (cf. Vidal-Puig et al. 1997).

Nucleolar size in neurons is related to the circadian rhythms (Pébusque et al. 1981) as well as in human lymphocyte (Berger and Berger 2002). Age-dependent changes in nucleoli (Dayan 2002) reflect metabolic activity in cells. Thus, the alternations in nucleoli rhythms can be a marker of senescence, but the regulation of rRNA synthesis does not seem to be the primary source of biorhythm alterations.

As the characteristics of suprachismatic nuclei alter in the aged (both humans and animals) and because this structure is a pacemaker of many 
circadian oscillations, such age-related changes could be the source of biorhythm ageing in mammals including human subjects. Histological and anatomical changes were reported in old animals and men (Hofman et al. 1988, 1996, Woods et al. 1993, Zhou and Swaab 1999), electrical activity of suprachiasmatic nucleus neurons taken from old animals have a lower amplitude(cf. Aujard et al. 2001), and suprachismatic nuclei transplants from young animals restore circadian behavioral rhythms in aged animals (Hurd et al. 1995, Cai et al. 1997, Ki and Satinoff 1998).

Clock genes are expressed in cells of suprachiasmatic nuclei and also many peripheral tissues. The mammalian circadian clock has a central pacemaker in suprachiasmatic nuclei which coordinates tissue - specific rhythms according to light input (Reppert and Weaver 2002). Products of the clock gene fall with age (Driver 2000). Circadian rhythms in mRNAs of per1, per2 and rCryl are similar in several tissues of young and old organisms but expression of Per1 and Per2 in the suprachiasmatic nucleus, which is induced by photic stimuli, is reduced with ageing; these and similar findings suggest that the molecular mechanisms of regulation of circadian rhythms are not altered by aging (Asai et al. 2001). The only difference documented for in vitro cultivated suprachiasmatic nucleus cells from an old laboratory rat was shortening of the free-running period as compared with those from young animals; circadian oscillations in some peripheral tissues were unaffected by ageing (Yamazaki et al. 2002).

Based on this observation, the genetic basis of circadian clocks seems to be unaffected by the process of ageing; the loss of biorhythms is on the cellular level. Pharmacological intervention is efficient when the exogenous substance (e.g. melatonin) is a substitute for a lower level of synthetic activity of old cells.

Table 1. Circadian rhythms during the human life

Age (years) Number of circadian cycles

10

50

60

70

80

90

100
3652

18262

21915

25567

29220

32872

36500

\section{BIORHYTHMS IN THE ELDERLY AND QUALITY OF LIFE}

The source of age-dependent changes of biorhythms can be the consequence of age-dependent impairment of light stimuli perception including diminution of retina cells and neurons in the suprachiasmatic nucleus but experiments on the effects of nursing mothers on young animals have reported that non-photic stimuli on rPer circadian expression in suprachiasmatic nuclei (Ohta et al. 2002) could play a role. Could non-photic stimuli substitute photic-stimuli and, therefore, improve the quality of life of older humans?

The organism of a 80-year man has passed through 29 thousand circadian cycles (Table 1) and, therefore, we can expect certain changes in this system and cannot be surprised at findings which tell us that poorly developed circadian rhythms are often associated with poor health (Watershouse and Minors 1996). As various published data demonstrate individual differences in age-related changes, circadian rhythms may be dependent on the 
quality of life of the investigated persons who are near the end of their life.

We can expect that the quality of biorhythms is a prognostic factor of years remaining as the loss of temporal structure in elderly is associated with a poor health state and decreased longevity and it is characterized by a decrease in circadian amplitude (Duffy and Feuers 1991). Increased circadian amplitude, which has been induced by food stimuli in experimental animals, is connected to prolonged healthful life span (Nelson and Halberg 1986, Nelson 1988). Similarly, the pharmacological effect of estrogen therapy in postmenopausal women leads to higher amplitude in certain biorhythms and enhance longevity but the mechanism of such effects is not known (Gudmundsson et al. 1999).

Although the process of ageing is a necessary characteristic of human life, we might view as slightly optimistic the findings of Mormount and Watershouse (2002), that the rest-activity circadian rhythm is independent of sex or that the type of primary tumour in cancer patients is independent of age. The quality of these circadian rhythms is positively correlated with physical, emotional and social functioning. Thus, we conclude that further studies on the health and social care systems, could benefit human healthy longevity.

Received $26^{\text {th }}$ February 2003.

Published online $19^{\text {th }}$ March 2003.

\section{REFERENCES}

Aujard F., E.D. Herzog, G.D. Block: Circadian rhythms in firing rate of individual suprachiasmatic nucleus neurons from adult and middle-aged mice. Neuroscience 106: 255-261, 2001.

Akbulut K.G., B. Gonul, H. Akbulut: The effects of melatonin on humoral immune responses of young and aged rats. Immunol. Invest. 30: 1720, 2001.

Asai M., Y. Yoshinobu, S. Kaneko, A. Mori, T. Nikaido, T. Moriya, M. Akiyama, S. Shibata: Circadian profile of Per gene mRNA expression in the suprachiasmatic nucleus, paraventricular nucleus, and pineal body of aged rats. J. Neurosci. Res. 66: 1133-1139, 2001.

Atkinson G., A. Coldwells, T. Reilly, J. Waterhouse: Effects of age on circadian rhythms in physical performance and mood states. J. interdiscipl. Cycle Res. 23: 186-188, 1992.
Atkinson G., K. Wine, G. Nold, U. Sasse, B. Lemmer: Effects of age on social blood pressure and heart rate rhythm in patients with primary hypertension. Chronobiol. Int. 11: 3544, 1994.

Berger J.: Haematological preclinical recording of adverse drug reactions - current status, problems, and needs. Part I. Standardization of experiments in relation to haematological examination. Fol. haematol. 114: 1-15, 1987.

Berger Z. and J. Berger: Time structure of lymphocyte nucleoli. Haematol. J. 3, Suppl. 1, 373, 2002.

Billiard M.: Circadian rhythm modifications in ageing. Sleep Disorders in the Elderly. In Facts and Research in Gerontology, Vol. 7, 1993, pp. 69-76.

Blask D.E., R.T. Dauchy, L.A. Sauer, J.A. Krause, G.C. Brainard: Light during darkness, melatonin suppression and cancer progression. Neuroendocrinol. Lett. 23, Suppl 2:52-56, 2002.

Bougrine S, R. Mollard, G. Ignazi, A. Coblentz: Appropriate use of bright light promotes a durable adaptation to night-shifts and accelerates readjustment during recovery after a period of night-shifts. Work Stress 9: 314-326, 1995.

Brainard G.C., M.D.Rollag, J.P.Hanifin: Photic regulation of melatonin in humans: ocular and neural signal transduction. J. Biol. Rhythms 12:537-546, 1997.

Brock M.A.: Chronobiology and ageing. J. amer Geriatr Soc 39: 74-91, 1991.

Bubenik G.A.: Gastrointestinal melatonin: localization, function, and clinical relevance. Dig. Dis. Sci.. 47: 2336-2348, 2002.

Cai A, K. Scarbrough, D.A. Hinkle, P.M. Wise: Fetal grafts containing suprachiasmatic nuclei restore the diurnal rhythm of $\mathrm{CRH}$ and POMC mRNA in aging rats. Am. J. Physiol. 273: R1764-R1770, 1997.

Cherif H., J.L. Tarry, S.E. Ozanne, C.N. Hales: Ageing and telomeres: a study into organ- and gender-specific telomere shortening. Nucleic Acid Res. 31: 1578-1583, 2003.

Collins A, L. Yuan, T.L. Kiefer, Q. Cheng, L. Lai, S.M. Hill: Overexpression of the MT1 melatonin receptor in MCF-7 human breast cancer cells inhibits mammary tumor formation in nude mice. Cancer Lett. 189:49-57, 2003.

Czeisler C.A., M. Dumon, J.F. Duffy, J.D. Steinberg, G.S. Richardson, E.N. Brown, R. Sanchez, C.D. Rios, J.M. Ronda: Association of sleep-wake habits in older people with changes in output of circadian pacemaker. Lancet 340: 933-936, 1992.

Czeisler C.A., J.F. Duffy, T.L. Shanahan, E.N. Brown, J.F. Mitchell, D.W. Rimmer, J.M. Ronda, E.J. Silva, J.S. Allan, J.S. Emens, 
D.J. Dijk, R.E. Kronauer: Stability, precision, and near-24-hour period of the human circadian pacemaker. Science 284: 2177-2181, 1999.

Davis T., S.K. Singhrao, F.S. Wyllie, M.F. Haughton, P.J. Smith, M. Wiltshire, D. Wynford-Thomas, C.J. Jones, R.G. Faragher, D. Kipling: Telomere-based proliferative lifespan barriers in Werner-syndrome fibroblasts involve both p53-dependent and p53-independent mechanisms. J. Cell Sci. 116: 1349-1357, 2003.

Dayan D., M. Vered, S. Sivor, Y. Hiss, A. Buchner: Age-related changes in proliferative markers in labial salivary glands: a study of argyrophilic nucleolar organizer regions (AgNORs) and Ki-67. Exp. Gerontol. 37: 841-850, 2002

Duffy J.F. and C.A. Czeisler: Age-related change in the relationship between circadian period, circadian phase, and diurnal preference in humans. Neurosci. Lett 318: 117-120, 2002.

Duffy P.H. and R.J. Feuers: Biomarkers of aging: changes in circadian rhythms related to the modulation of metabolic output. Biomed. Environ. Sci. 4:182-191, 1991.

Edmunds Jr L.N.: Clocks, cell cycles, cancer, and aging. Role of the adenylate cyclase-cyclic AMP-phosphodiesterase axis in signal transduction between circadian oscillator and cell division cycle. Ann. N. Y. Acad. Sci. 719: 7796, 1994.

Forsling M.L., H. Montgomery, D. Halpin, R.J.Windle, D.F.Treacher: Daily patterns of secretion of neurohypophyseal hormones in man - effect of age. Exper. Physiol. 83: 409-418, 1998.

Gander P.H., D. Nguyen, M.R. Rosekind, L.J. Connell: Age, circadian rhythms, and sleep loss in flight crews. Aviation Space Environm. Med. 64: 189-195, 1993.

Garciapatterson A., M. Puigdomingo, S.M. Webb: 30 years of human pineal research - do we know its clinical relevance. J. Pineal Res. 20: 1-6, 1996.

Gudmundsson A., B. Goodman, S. Lent, S. Barczi, A. Grace, L. Boyle, W.B. Ershler, M. Carnes: Effects of estrogen replacement therapy on the circadian rhythms of serum cortisol and body temperature in postmenopausal women. Exp Gerontol. 34:809-818, 1999.

Hinton D.R., A.A. Sadun, J.C. Blanks, C.A. Miller: Optic nerve degeneration in Alzheimer's disease. N. Engl. J. Med 315: 485-487, 1986.

Hofhaus G., M. Berneburg, M. Wulfert, N. Gattermann: Live now - pay by ageing: high performance mitochondrial activity in youth and its age-related side effects. Exp. Physiol. 88:167-74, 2003.

Hofman M.A., E. Fliers, E. Goudsmit, D.F. Swaab: Morphometric analysis of the suprachiasmatic and paraventricular nuclei in the human brain: sex differences and age-dependent changes. J. Anat. 160:127-143, 1988.

Hofman M.A., J.N. Zhou, D.F. Swaab: Suprachiasmatic nucleus of the human brain: an immunocytochemical and morphometric analysis. Anat. Rec. 244:552-562, 1996.

Hurd M.W., K.A. Zimmer, M.N. Lehman, M.R. Ralph: Circadian locomotor rhythms in aged hamsters following suprachiasmatic transplant. Am. J. Physiol. 269: R958-R968, 1995.

Ibata Y, H. Okamura, M. Tanaka, Y. Tamada, S. Hayashi, N. Iijima, T. Matsuda, K. Munekawa, T. Takamatsu, Y. Hisa, Y. Shigeyoshi, F. Amaya: Functional morphology of the suprachiasmatic nucleus. Front. Neuroendocrinol. 20: 241-68, 1999.

Illnerova H. and A. Sumova: Photic entrainment of the mammalian rhythm in melatonin production. J. Biol. Rhythms 12: 547-555, 1997.

Khavinson V.K.: Peptides and ageing. Neuroendocrinol. Lett. 23, Suppl 3: 11, 2002.

Li H. and E. Satinoff: Fetal tissue containing the suprachiasmatic nucleus restores multiple circadian rhythms in old rats. Am. J. Physiol. 275: R1735-1744, 1998.

Lunenfeld B.: Replacement therapy in the aging male. J. Endocrinol. Invest. 25, Suppl 10: 2-9, 2002.

Mastronardi C.A., W.H. Yu, S.M. McCann: Resting and circadian release of nitric oxide is controlled by leptin in male rats. Proc. Natl. Acad. Sci. U. S. A. 99: 5721-5726, 2002.

Mayo J.C., R.M. Sainz, I. Antoli, F. Herrera, V. Martin, C. Rodriguez: Melatonin regulation of antioxidant enzyme gene expression. Cell Mol. Life Sci. 59: 1706-1713, 2002.

Meyer-Bernstein E.L., A.E.Jetton, S.I. Matsumoto, J.F. Markuns, M.N. Lehman, E.L. Bitman: Effects of suprachiasmatic transplants on circadian rhythms of neuroendocrine function in golden hamsters. Endocrinology 140: 207-218, 1999.

Miquel J.: Can antioxidant diet supplementation protect against age-related mitochondrial damage? Ann. N. Y. Acad. Sci. 959:508-516, 2002.

Mishuma K., M. Okawa, Y. Hishikawa, S. Hozumi, H. Hori, K. Takahashi: Morning bright light therapy for sleep and behavor disroders in elederly patientes with dementia. Acta Psychiatr. Scand. 89: 1-7, 1994.

Monk T.H., C.F. Reynolds, D.J.Buysse, C.C. Hoch, D.B. Jarrett, J.R.Jennings, D.J.Kupfer: Circadian characteristics of healthy 80 year olds and their relationship to objectively recorded sleep. J. Gerontol. 46: M171-M175, 1991. 
Mormont M.C. and J. Waterhouse: Contribution of the rest-activity circadian rhythm to quality of life in cancer patients. Chronobiol. Int. 19:313323, 2002.

Mrosovsky N.: Locomotor activity and non-photic influences on circadian clocks. Biol Rev Camb Philos Soc 71: 343-372, 1996.

Nelson W.: Food restriction, circadian disorder and longevity of rats and mice. J. Nutr. 118: 286289, 1988.

Nelson W, Halberg F.: Meal-timing, circadian rhythms and life span of mice. J. Nutr. 116: 2244-2253, 1986.

Ohta H., S. Honma, H. Abe, K. Honma: Effects of nursing mothers on rPer1 and rPer2 circadian expressions in the neonatal rat suprachiasmatic nuclei vary with developmental stage. Eur. J. Neurosci. 15: 1953-1960, 2002.

Olde Rikkert M.G. and A. S. Rigaud: Melatinin in elderly patients with insomnia. A systematic review. Z. Gerontol. Geriatr 34: 491-497, 2001.

Pandi-Perumal S.R., L. K. Seils, L. Kayumov, M.R. Ralph, A. Lowe, H. Moller, D.F.Swaab: Senescence, splee, and circadian rhythms. Ageing Res. Rev. 1: 559-604, 2002.

Pasqualetti P and R. Casale: No influence of aging on the circadian rhythm of erythropoietin in healthy subjects. Gerontology 43: 206-209, 1997.

Pébusque M.J., A. Robaglia, R. Seïte: Diurnal rhythm of nucleolar volume in sympathetic neurons of the rat superior cervical ganglion. Eur. J. Cell Biol. 24: 128-130, 1981.

Pittendrigh C.S. and D.H. Minis: Circadian systems: longevity as a function of circadian resonance in Drosophila melanogaste. Proc. Nat. Acad. Sci. USA 69: 1537-1539, 1972.

Pollack C.P., D. Perlic, J. P. Lisner: Daily sleep reports and circadian rest-activity cycles of elderly community residents with insomnia. Biol. Psychiat. 32: 1019-1027, 1992.

Reinberg A., P. Andlauer, J. de Prins, W. Malbecq, N. Vieux, P. Bourdeleau: Desynchronization of the oral temperature circadian rhythms and intolerance to shift work. Nature 308: 272-274, 1984.

Rensing L., U. Meyer-Grahle, P. Ruoff: Biological timing and the clock metaphor: oscillatory and hourglass mechanisms. Chronobiol. Int.18: 32969, 2001.

Reppert S.M. and D.R. Weaver: Coordination of circadian timing in mammals. Nature 418: 935941, 2002.

Reynolds C.F., T.H. Mon, C.C. Hoch, J.R. Jennings, D.J. Buysse, P.R. Houck, D.B. Jarrett, D.J. Kupfer: EEG sleep in the healthy "Old Old": A comparison with the "Young Old" in visually scored and automated (period) measures. J. Gerontol. 46: M39-M46, 1991.

Richardson G.S., M.A.Carkadson, E.J. Orav, W.C. Dement: Circadian variation of sleep tendency in elderly and young subjects. Sleep 5: 82-94, 1982.

Rozman C., E. Feliu, L. Berga, J.C. Reverter, C. Climent, M.J. Ferran: Age-related variations of fat tissue fraction in normal human bone marrow depend both on size and number of adipocytes: a stereological study. Exp. Hematol. 17: 34-37, 1989.

Sack RL, Lewy AJ.: Melatonin as a chronobiotic: treatment of circadian desynchrony in night workers and the blind. J. Biol. Rhythms 12:595603, 1997.

Saretzki G. and T. von Zglinicki: Replicative aging, telomeres, and oxidative stress. Ann. N. Y. Acad. Sci. 959:24-29, 2002.

Sastry P.S. and P. Parikh: The earlier age of onset of malignancy in developing world is related to overall infection burden and could be due to the effect on telomere length. Med. Hypotheses 60: 573-574, 2003.

ShanahanT.L., J.M. Zeitzer, C.A. Czeisler: Resetting the melatonin rhythm with light in humans. J. Biol. Rhythms 12: 556-567, 1997.

Sharma M., J. Palacio-Bois, G. Schwartz, H. Iskandar, M. Thakur, R. Quirion, N.P. Nair: Circadian rhythms of melatonin and cortisol in aging. Biol. Psychiat. 25: 306-310, 1989.

Sletvold O., O.D. Laerum, T. Riise: Rhythmic variations of different hemopoietic cell lines and maturation stages in aging mice. Mech. Ageing Dev. 42: 91-104, 1988.

Swoyer J., P. Irvine, L. Sackett-Lundeen, L. Conlin, D.J. Lakatua, E. Haus: Circadian hematologic time structure in the elderly. Chronobiol. Int. 6: 131-137, 1989.

Terron M.P., J. Cubero, J.M. Marchena, C. Barriga., A.B. Rodriguez: Melatonin and ageing: In vitro effect of young and mature ring dove physiological concentrations of melatonin on the phagocytic function of heterophils from old ring dove. Exp. Gerontol. 37: 421-426, 2002.

Thomas D.R. and A. Milles: Melatonin secretion and age. Biol. Psychiat. 25: 363-368, 1989.

Troen B.R.: Biology of aging. Mount Sinai J. Med. 70: 2-22, 2003.

Usui S.:Gradual changes in environmental light intensity and entrainment of circadian rhythms. Brain Dev. 22, Suppl 1: S61-S64, 2000.

Van Someren E.J.W., M. Mirmiran, D.F.Swaab: Non-pharmacological treatment of sleep and wake disturbances in aging and Alzeheimer's disease - chronobiological perspectives. Behav. Brain Res. 57: 235-253, 1993. 
Van Sommeren E.J., R.J. Raymann, E.J. Scherder, H.A. Daanen, D.F. Swaab: Circadian and agerelated modulation of thermoreception and tempoerature regulation: mechanisms and functional implications. Ageing Res. Rev. 1: 721-778. 2002.

Vidal-Puig A.J., R.V. Considine, M. Jimenez-Linan, A. Werman, W.J. Pories, J.F. Caro, J.S. Flier: Peroxisome proliferator-activated receptor gene expression in human tissues. Effects of obesity, weight loss, and regulation by insulin and glucocorticoids. J. Clin. Invest. 99: 2416-2422, 1997.

Waterhouse J.M. and D.S. Minors: Circadian rhythms in the neonate and in old age: What do they tell us about the development and decay of the body clock in human? Braz. J. med. biol. Res. 29: 87-94, 1996.

Woods W.H., E.W. Powell, A. Andrews, C.W. Ford Jr.: Light and electron microscopic analysis of two divisions of the suprachiasmatic nucleus in the young and aged rat. Anat. Rec. 237: 71-88, 1993.

Witting W, M. Mirmiran, N.P. Bos, D.F. Swaab: The effect of old age on the free-running period of circadian rhythms in rat. Chronobiol Int. 11: 103-112, 1994.

Weinert D.: Age-dependent changes of the circadian system. Chronobiol. Int.17:261-283, 2000.

Weitzman E.D. and D.F. Kripke: Experimental 12hour shift of the sleep-wake cycle in man: Effects on sleep and physiological rhythms. In L.C. Johnson, D. I. Tepas, W.P. Colquhoun, M.J.Colligan (eds): Variations in Work-Sleep Schedules: Effects on Health and Performance. Advances in Sleep Research, Vol. 7. Spectrum Publ., New York 1981, pp. 125-149.

Winczyk K, M. Pawlikowski, J.M. Guerrero, M. Karasek: Melatonin regulation of antioxidant enzyme gene expression. Cell Mol Life Sci. 59: 1706-1713, 2002.

Zeitzer J.M., J.E. Daniels, J.F. Duffy, E.B. Klerman, T.L. Shanahan, D.J. Dijk, C.A. Czeisler: Do plasma melatonin concentrations decline with age? Am. J. Med. 107: 432-436, 1999.

Zhou J.N. and D.F. Swaab: Activation and degeneration during aging: a morphometric study of the human hypothalamus. Microsc. Res. Tech. 44: 36-48, 1999.

\section{Address:}

Josef Berger, Institute of Biophysics and Medical Engineering, Faculty of Health and Social Studies, Branišovská 31, 37005 České Budějovice, Czech Republic; berger@jcu.cz 